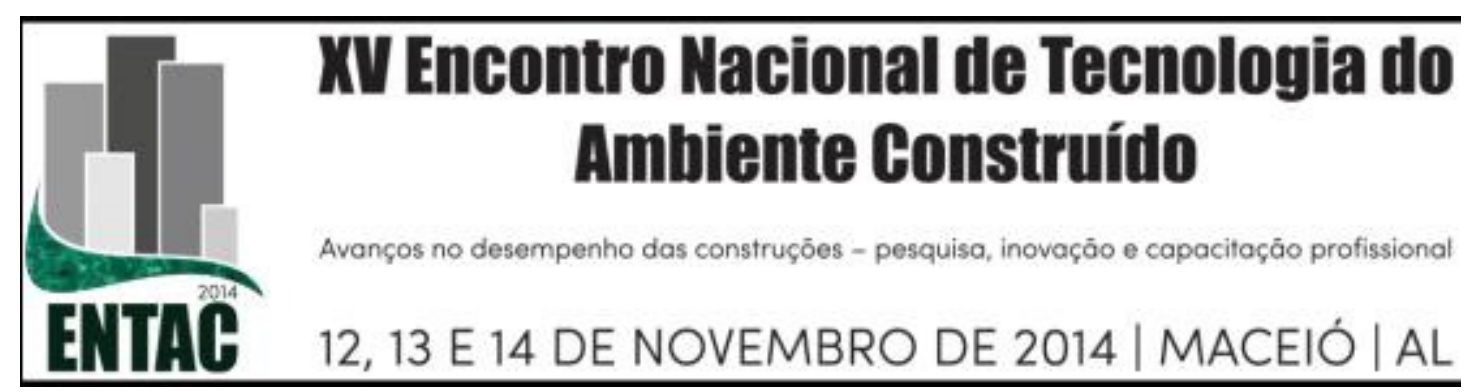

\title{
ANÁLISE EXPERIMENTAL DE EMENDAS TRACIONADAS DE BARRAS DE MADEIRA LAMINADA PREGADA DE PINUS spp.
}

\author{
RECCO, Emanuelle Graça; PLETZ, Everaldo; MOURA, Jorge Daniel de Melo
}

(1) Universidade Estadual de Londrina, emanuellegracarecco@yahoo.com.br, (2) Universidade Estadual de Londrina, pletz@,uel.br, (3) Universidade Estadual de Londrina, jordan@,uel.br.

\begin{abstract}
RESUMO
Tendo em vista que grande parte das moradias brasileiras apresenta coberturas inadequadas, com componentes em madeira geralmente provenientes de florestas nativas e processo construtivo artesanal (decorrente de déficit de mão de obra qualificada para incorporação da pré-fabricação), atualmente tem-se grande necessidade de desenvolvimento de novos sistemas construtivos com uso de madeira de florestas plantadas, a fim de viabilizar seu uso em estruturas e agregar valor a esta matéria prima com grande disponibilidade no mercado. O Pinusbr spp apresenta grande quantidade de defeitos naturais e para sua utilização em estruturas é necessário sua classificação. A proposta da pesquisa, na qual este trabalho está inserido, é a utilização de madeira serrada Pinus spp no sistema caibro treliçado em MLP (Madeira laminada pregada), a fim de possibilitar o uso de peças de menor comprimento e seção transversal. Em uma primeira etapa da pesquisa, dedicada ao desenvolvimento do produto, foram ensaiados dois tipos de caibros treliçados. Observaram-se melhorias de desempenho, do primeiro para o segundo protótipo e detectou-se que o maior gargalo encontra-se nas emendas das barras tracionadas em MLP. Desta forma, este trabalho tem como objetivo apresentar uma análise dos resultados de ensaios experimentais das emendas das vigas em MLP localizadas no banzo inferior da tesoura, local mais solicitado à tração. Foram ensaiados 07 modelos para cada variação de pino metálico, sendo elas, prego liso, prego liso com ponta dobrada e prego tipo ardox, totalizando 21 modelos. Esses resultados terão grande relevância para as próximas etapas da pesquisa, que compreendem a análise experimental do sistema caibro treliçado em MLP e, consequentemente a otimização estrutural.
\end{abstract}

Palavras Chave: Pinus spp, MPL (madeira laminada pregada), caibro treliçado, pré-fabricação.

\begin{abstract}
Considering that most Brazilian houses have inadequate roof structure, usually with wood components from native forests and handmade construction process (implications of shortage of skilled labor and of not incorporating prefabricated systems), there is nowadays a great need for development of new building systems using wood from planted forests in order to enable their use in structures and add value to this raw material that now is of great availability in the market. Pinus spp presents lots of natural defects and for structural use classification is necessary. The objective of this research, from which this paper is a part, is to enable the use of smaller cross sections and lengths of Pinus spp in nailed laminated truss rafter system. In a first stage of the research, dedicated to product development, so far two types of trussed rafters were tested. It was observed performance improvements from the first to the second prototype, and it was found that currently the biggest issue to be addressed is the butt joint under tensile stresses. This paper aims to present an experimental analysis of the nailed laminated timber beams butt joints located on bottom chord of the trusses, where the tension stresses are the highest. Three variations of metal pins were tested, common nail, common nail with bent tip and ardox nail. Seven specimens of each variation were tested totaling 21 specimens. These results are of great relevance for the next steps of the research which include the experimental analysis of truss rafter system in MLP and hence the structural optimization.
\end{abstract}

Keywords: Pine wood, Nail laminated timber, trussed rafter, prefabrication. 


\section{INTRODUÇÃO}

Ao considerar as circustâncias sociais do déficit habitacional brasileiro e a precariedade das condições de moradia na atualidade, verifica-se que existe um vasto campo de pesquisa para investigação da fabricação e utilização de sistemas construtivos préfabricados, com madeira de plantios florestais, sobretudo para a habitação de interesse social. Com efeito, no setor da construção civil tem se evidenciado cada vez mais o caráter de imprescindibilidade do desenvolvimento de produtos e processos que promovam a redução de custos e melhoria da qualidade dos sistemas construtivos e das habitações em geral.

Segundo DAMIANO e SALES (2004), a forma de se executar um telhado no Brasil, no século 20, permancece ainda hoje inalterada, cristalizada em costumes de comércio, consumo e carpintaria, baseados em tradições de execução que passam de pai para filho, habituados ao uso de exageradas bitolas das poucas espécies ainda existentes de madeiras conhecidas (de alta qualidade) e comumente utilizadas.

As madeiras de reflorestamento ocupam espaço cada vez maior no mercado, em virtude de seu crescimento rápido e também devido à escassez crescente da madeira nativa, que tem se tornando mais onerosa e menos disponível. Em razão disso, deve-se reunir esforços e aprimorar os estudos no sentido de agregar valor à madeira de reflorestamento, aumentar sua área plantada, fomentar a construção em madeira, contribuindo, dentre outras coisas, para a diminuição da emissão de dióxido de carbono na atmosfera, mitigando os problemas ambientais, sociais e econômicos com uma maneira mais eficaz (BRITO et. al, 2010).

A MLP - madeira laminada pregada consiste na justaposição de camadas de tábuas através da utilização de pregos como elementos de ligação para a união das peças de madeira. O emprego de peças compostas de madeira formadas pela união de peças de dimensões comerciais vem alcançando importância no setor de estruturas de madeira do Brasil, principalmente devido à gradativa escassez de peças de grandes dimensões. As peças compostas de madeira serrada solidarizadas continuamente por pregos possuem vasta aplicação como material estrutural e apresentam como principais vantagens a facilidade e o baixo custo de produção (GÓES \& DIAS 2005).

O sistema de cobertura em caibro treliçado ainda é pouco conhecido no Brasil, porém muito difundido em outros países. A principal característica desse sistema revela-se na eliminação das terças e tesouras tradicionais e adoção de caibros na forma treliçada, fato que deu origem ao nome do sistema. A trama é formada apenas pelas ripas, as quais participam do sistema de contraventamento das tesouras, que constituem a estrutura de apoio. São espaçadas entre si geralmente de $100 \mathrm{~cm}$ e permitem que as edificações venham a ter vãos que variam de 6 a 12 metros. Os grandes vãos são possíveis devido à grande quantidade de tesouras, distribuindo melhor os esforços atuantes entre os demais elementos estruturais. (VALLE, 2011).

Verifica-se que, nas estruturas pré-fabricadas, as ligações são de extrema importância. De acordo com DUARTE (2004), elas viabilizam o transporte das peças, permitem sua união, sendo responsáveis pela continuidade e pelo comportamento global das construções, além de serem a causa da maioria dos problemas e falhas estruturais.

Entre os elementos estruturais de madeira, existem basicamente três tipos de ligações: ligações por contato, que são formadas apenas pelo contato entre as peças de madeira; ligações coladas, fabricadas a partir da união entre peças de madeira pela ação de um adesivo colocado entre elas, e; ligações mecânicas, em que há penetração do elemento de ligação nas peças de madeira. $\mathrm{O}$ estudo sobre o comportamento dessas ligações é importante pois permite identificar seus problemas e apontar as soluções, sendo possível melhorar a capacidade de carga, sua rigidez e ductilidade. Como resultado destes 
estudos, tem-se uma evolução ou mesmo a criação de novos arranjos e/ou elementos de ligações (DUARTE, 2004).

No processo de ruptura das ligações mecânicas entre as peças de madeira utilizando pinos e solicitadas a carregamentos monotônicos, HALLER (1998) descreve em quatro fases o comportamento destas ligações: 1- Deslocamentos sem transferência de carga devido aos erros de fabricação; 2- Fase elástica, com comportamento elástico linear da madeira e do pino; 3- Fase plástica, com deslocamentos irreversíveis devido ao escoamento do pino ou fissuras na madeira, e; 4- Ruptura completa da ligação. A partir desta identificação são propostas mudanças nas ligações com o objetivo de corrigir estas falhas.

Como a madeira é um material frágil na tração, as ligações tendem a apresentar este mesmo comportamento se a ruptura acontecer na madeira. De acordo com HALLER (1998), a única forma de aumentar a ductilidade das ligações em estruturas de madeira consiste na utilização de elementos de ligação mecânica que permitam a formação de rótulas plásticas antes da ruptura.

Com relação a ductilidade das estruturas de madeira, quando as ligações são muito resistentes e rígidas, SMITH E FOLIENTE (2002) afirmaram que a ruptura nessas peças tende a acontecer de forma brusca e não desejada. Diante disso, as ligações devem ser escolhidas e projetadas, a fim de que atuem como fator responsável pela ductilidade das estruturas e não visando apenas a transmissão dos esforços solicitantes com elevada resistência e rigidez. Com efeito, a ductilidade das ligações é caracterizada pelo comportamento da curva de tensão deformação. Um comportamento dúctil para as ligações só é possível quando a ruptura ocorre depois de elevadas deformações plásticas dos elementos de ligação.

Os elementos usados nas ligações mecânicas são divididos em 02 grupos, os elementos tipo pinos e os conectores. Os pregos são os pinos mais comuns e podem ser encontrados no mercado em várias formas, tipos e tamanhos. Eles podem ser fabricados com uma, duas cabeças e até mesmo sem cabeça. O fuste dos pregos pode ser de seção circular (prego comum), quadrada (prego de marinheiro) ou trabalhada mecanicamente dando origem a fustes aneladas (prego anelar) ou helicoidais (prego ardox). Eles podem ser revestidos com o objetivo de aumentar sua resistência à oxidação ou à carga axial (DUARTE, 2004).

Para propor um sistema alternativo de cobertura em madeira, com fundamento em critérios de racionalização da construção, é importante levar em consideração um método de dimensionamento eficiente. Nesse aspecto, podem ser mencionadas as recomendações da norma NBR 7190-97 (Projeto de Estruturas de Madeira), baseadas no método dos estados limites. Além de estados limites últimos relacionados à resistência dos materiais, a norma prevê a restrição de deslocamentos, o que previne $\mathrm{o}$ comprometimento estético e o mau funcionamento de equipamentos e instalações, evitando danos aos materiais de acabamento ou às partes não estruturais da construção (CALIL JR. et al., 2003).

Segundo WOOD HANDBOOK (1999), os pregos podem resistir à carga transversal, à carga axial ou uma combinação das duas. Nas ligações pregadas, desde que grandes deslocamentos não sejam tolerados na ligação, a influência da resistência à carga axial na resistência à carga transversal pode ser desconsiderada. Nos pregos anelares e ardox, que possuem os fustes trabalhados mecanicamente, há um aumento na superfície de contato entre o prego e a madeira sem que haja um aumento no peso do prego. A resistência à carga axial desses pregos é sempre maior que a dos pregos comuns de mesmo diâmetro. A norma européia EUROCODE 5 (2004) denomina esse comportamento das ligações por pinos metálicos de efeito corda (rope effect). Ao 
contrário da norma européia, a norma brasileira não considera o efeito corda na determinação da resistência das ligações pregadas.

No processo experimental de utilização de madeira serrada Pinus spp no sistema caibro treliçado em MLP (Madeira laminada pregada), em pesquisa prévia desenvolvida no departamento da Universidade Estadual de Londrina (artigo sendo publicado nesse mesmo evento) foram ensaiados 02 exemplares, sendo que o primeiro apresentou ruptura com carregamento de $7,07 \mathrm{kN}$, devido a uma fragilidade na ligação entre perna e linha. Ensaios dessa ligação foram realizados e aplicados no segundo exemplar, que obteve melhorias com carregamento de ruptura da estrutura de $13,6 \mathrm{kN}$, cuja ruptura ocorreu em uma das emendas da barra tracionada. Em vista disso, este trabalho tem como objetivo principal a análise do desempenho das emendas de viga em MLP de Pinus spp, quando submetidas à tração, utilizando 03 composições diferentes de pinos metálicos. Esses resultados contribuirão para a escolha do prego adequado a ser utilizado posteriormente no ensaio do sistema caibro treliçado em MLP.

\section{MATERIAIS E MÉTODOS}

A madeira utilizada no ensaio foram pranchas já secas de Pinus spp, com umidade em média de $12 \%$, que possuíam dimensões médias de $4 \mathrm{~cm}$ de espessura, $28 \mathrm{~cm}$ de largura e $300 \mathrm{~cm}$ de comprimento. As pranchas foram desdobradas em quatro tábuas. As peças foram primeiramente classificadas visualmente com o auxílio de um Manual de classificação visual de peças estruturais de madeira tipo Pinus spp publicado em artigo e livro (MOURA et al., 2012), elaborado de acordo com a norma brasileira NBR 1170090 e as regras de classificação visual americanas do SPIB (Southern Pine Inspection Bureau) e da norma ASTM D245-93.

Para a determinação dos módulos de elasticidade efetivos das peças de Pinus spp foram adotados os procedimentos recomendados no Anexo B da NBR 7190-97. O lote de Pinus spp utilizado na presente pesquisa foi classificado como C25.

Os modelos foram confeccionados com madeira de dimensões estruturais, a fim de aproximar o experimento às estruturas realizadas na prática. Foram usados pregos $18 \times 36$ de 02 tipos, liso e ardox. Cada modelo apresenta dimensão final de $06 \mathrm{~cm} \times 14 \mathrm{~cm} \times 150 \mathrm{~cm}$, formado por uma composição de 05 peças de $02 \mathrm{~cm}$ de espessura, $14 \mathrm{~cm}$ de largura e comprimento variado, $65 \mathrm{~cm}$ e $85 \mathrm{~cm}$ nas camadas externas e $150 \mathrm{~cm}$ na camada interna (peça inteira), conforme ilustrado na Figura 1. Os pregos que fazem a conexão das lâminas de madeira estão dispostos a $02 \mathrm{~cm}$ da borda e $05 \mathrm{~cm}$ entre eles e as emendas, seguindo as recomendações mínimas de espaçamentos em ligações com pinos especificados na NBR 7190-97. São 09 pregos entre as emendas espaçadas de 20 cm (palmo do carpinteiro), e 12 pregos de cada lado, totalizando 33 pregos por modelo.

Figura 1. Detalhe do modelo

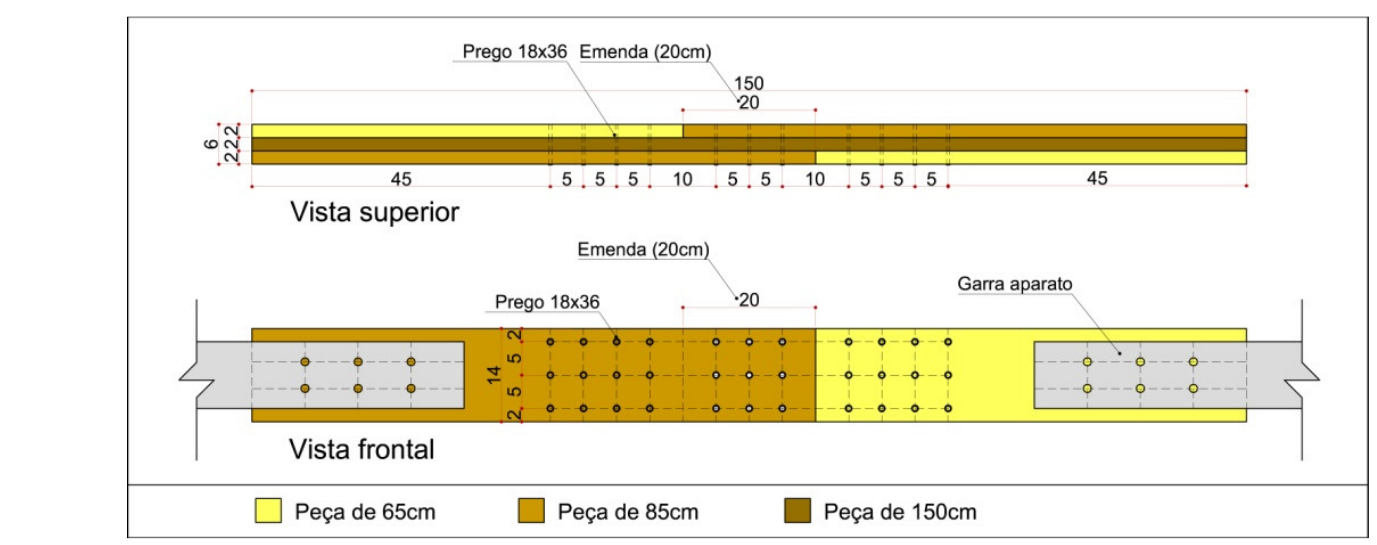

Fonte: Autores 
Foram organizados 03 grupos de modelos usando pregos com as três seguintes variações: prego liso, liso com ponta dobrada e prego ardox. Os grupos foram nomeados como PA para o prego liso, PB para o prego liso com ponta dobrada e PC para o tipo ardox. Foram designados 01 modelo gêmeo e 06 modelos para cada grupo, conforme recomendações do Anexo B da NBR 7190-97), totalizando 21 modelos.

Após cortadas nos comprimentos $65 \mathrm{~cm}, 85 \mathrm{~cm}$ e $150 \mathrm{~cm}$, as peças foram organizadas em grupos com módulos de elasticidade (MOE) similares. Foi realizada a pré-furação de acordo com a norma NBR 7190-97, que especifica para as coníferas broca com diâmetro mínimo de $0,85 \mathrm{~d}_{\mathrm{ef}}$, sendo $\mathrm{d}_{\mathrm{ef}} \mathrm{o}$ diâmetro efetivo medido nos pinos a serem utilizados, em milímetros. Para este procedimento foi elaborado um gabarito de modo a agilizar o processo (Figura 2).

Figura 2. Fotos do gabarito, pré-furação e pregação dos modelos.
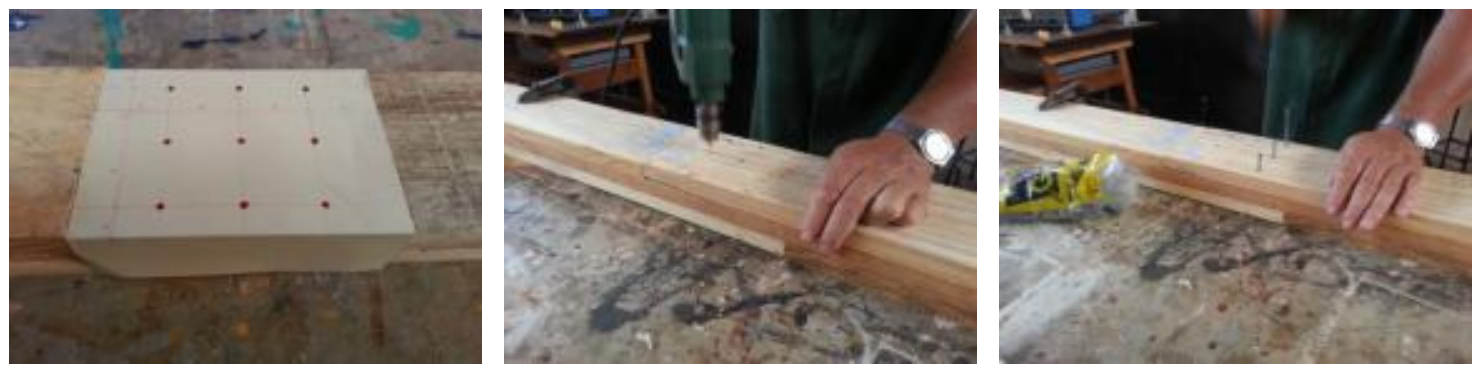

Fonte: Autores

Para o ensaio da tração dos modelos, foi desenvolvido um aparato, cujo principal cuidado foi manter as extremidades mais resistentes de modo a garantir a ruptura no trecho central. No projeto do aparato, levou-se em consideração economia e as condições existentes no laboratório.

Tanto para os conectores metálicos quanto para as garras que fixam o modelo, foram especificadas chapas de $1 / 4$ ". Eles se conectam às peças de madeira (barras inclinadas e modelo) através de parafusos de $1 / 2$ ". Para a rótula nas ligações e conexão das peças metálicas, utilizaram-se pinos de aço com diâmetro de 11/2" e, para o deslizamento do apoio na base, utilizaram-se rolamentos. (Figura 3)

Figura 3. Detalhe do aparato para realização do ensaio a tração.

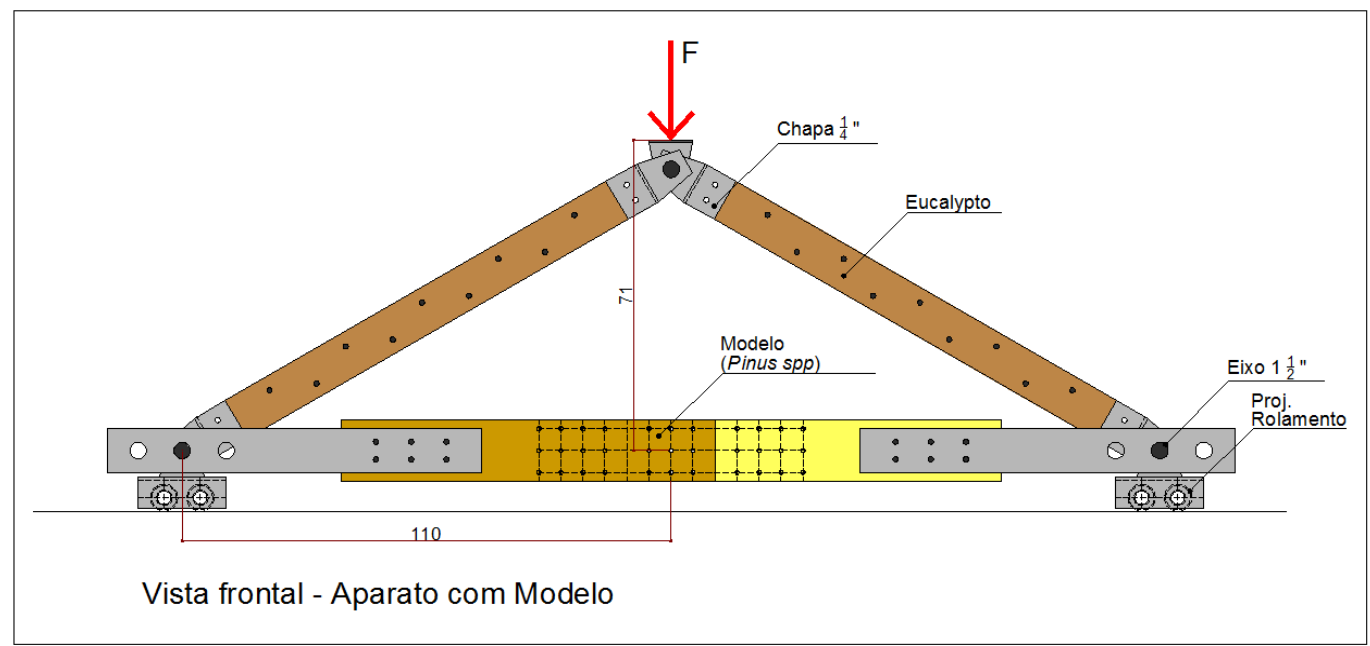

Fonte: Autores

Depois de confeccionadas as peças metálicas, o aparato foi montado no laboratório de modelos da Universidade. (Figura 4) 
Figura 4. Fotos das peças do aparato - rolamentos e conectores metálicos.
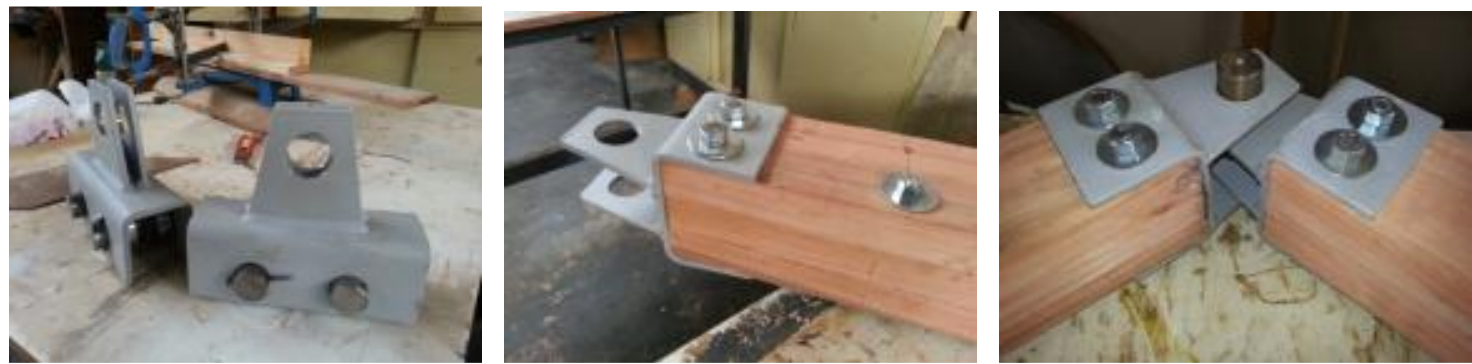

Fonte: Autores

A aplicação da carga foi feita com auxílio de um pórtico metálico com cilindro de atuação hidráulico. O carregamento foi registrado por célula de carga de $10 \mathrm{tf}$. $\mathrm{Na}$ sequência de instalação do aparato, foi regulada a altura da célula de carga, conforme apresentado na Figura 5. Utilizou-se para a aquisição de dados, o sistema computacional Lynx.

Figura 5. Fotos da célula de carga, pórtico metálico e montagem do aparato.
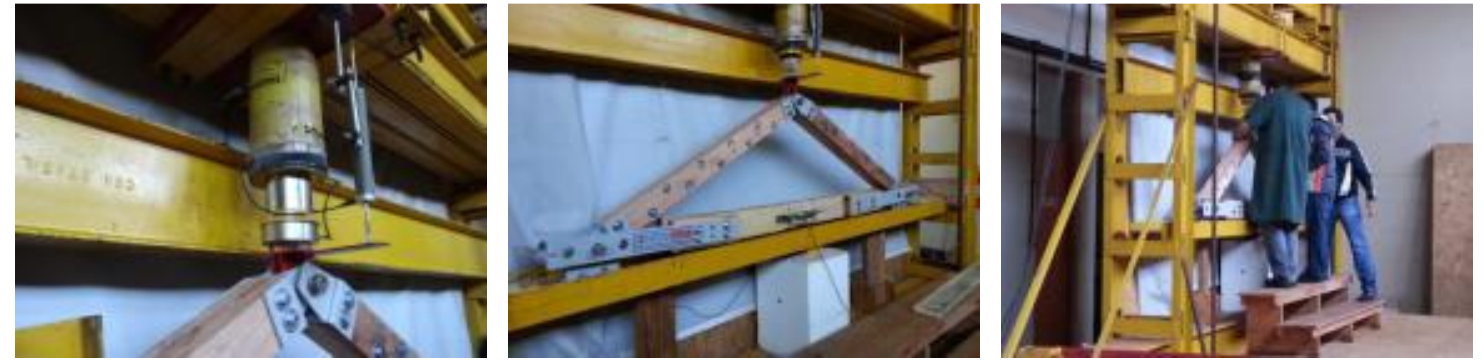

Fonte: Autores

O ensaio foi realizado conforme procedimentos do anexo C da NBR 7190-97 que, para a determinação da rigidez, a resistência da madeira deve ser estimada ( $\mathrm{ft}_{0, \text { est }}$ ) pelo ensaio destrutivo de um modelo gêmeo selecionado da mesma amostra a ser investigada. Conhecida a resistência estimada da amostra ( $\mathrm{ft}_{0, \mathrm{est}}$ ), o carregamento foi aplicado com dois ciclos de carga e descarga ( $10 \%$ e $50 \%$ da $\mathrm{ft}_{0, \text { est }}$ ).

Medidores de deslocamento (LVDTs) foram instalados no momento do ensaio, um de cada lado do modelo, para a medição do deslocamento da ligação. (Figura 6)

Figura 6. Fotos dos LVDTs, vista frontal e superior deles instalados nos modelos.
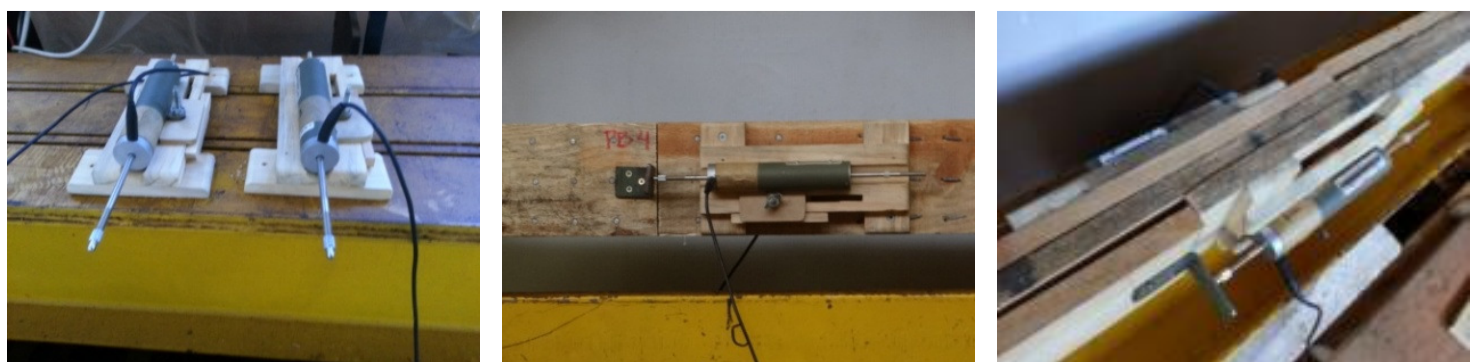

Fonte: Autores

\section{RESULTADOS E DISCUSSÃO}

Foram elaborados diagramas força $\mathrm{x}$ deformação específica, sendo encontradas a resistência e rigidez da emenda de cada modelo conforme especificações da NBR 719097. Apresenta-se na Figura 7 uma curva modelo do comportamento da ligação para este tipo de solicitação, incluindo a reta para determinação da resistência da ligação. 
Figura 7. Gráfico modelo do ensaio de tração da ligação Diagrama força $x$ deformação específica

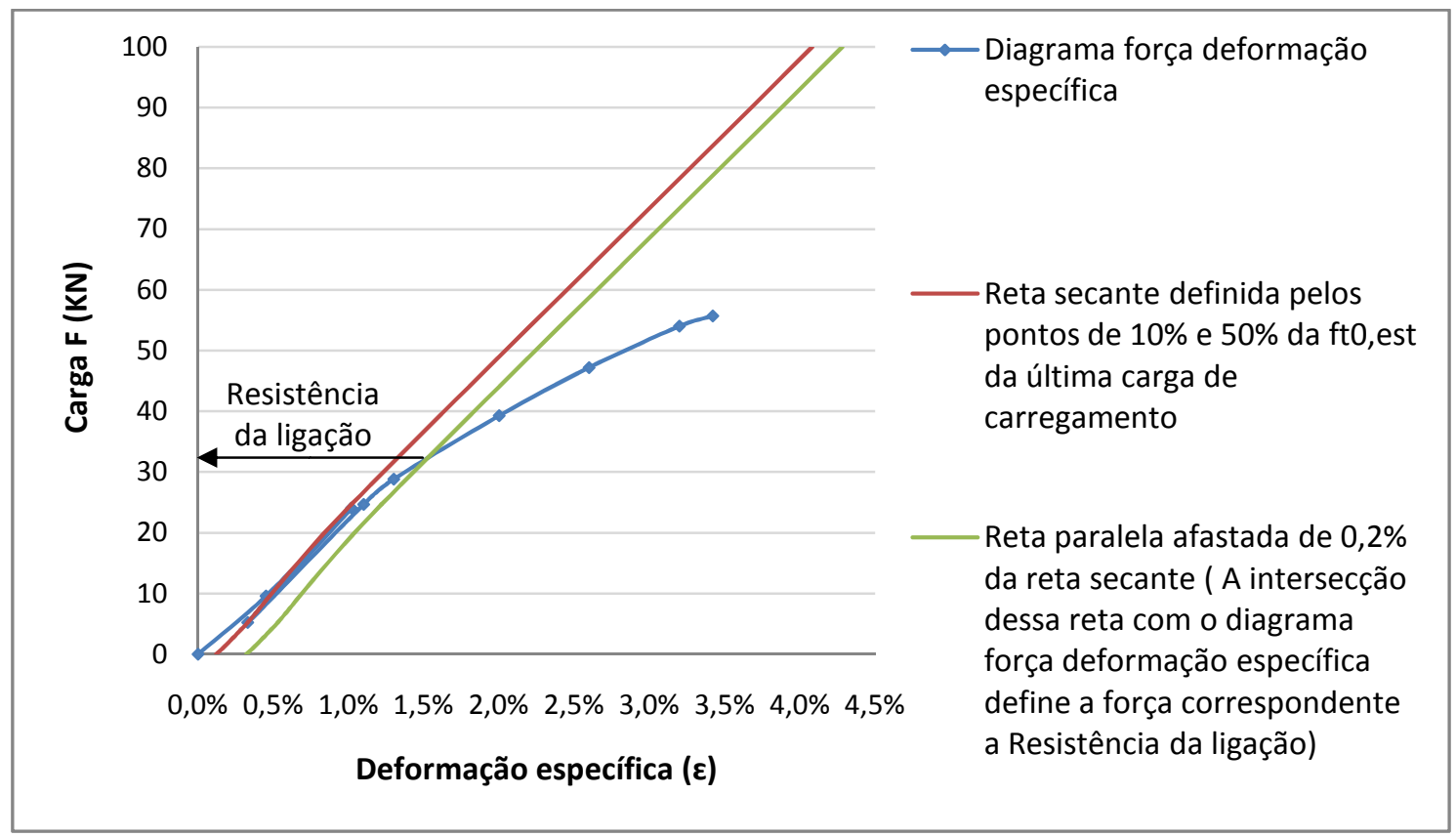

Fonte: Autores

Cabe observar que, na região central do tirante horizontal, no intervalo de $20 \mathrm{~cm}$ entre as duas emendas, a transmissão do esforço axial é realizada por duas lâminas, a central e uma externa. Uma parcela de esforço axial é transmitida pela lâmina central, por causa da sua continuidade, e a parcela restante deste esforço pela ligação pregada, que transfere de uma lâmina externa para outra. Sendo assim, por hipótese, assume-se que a ligação pregada nesta emenda em questão possua, em uma seção de corte, uma solicitação igual à metade do esforço normal existente na barra composta, conforme ilustrado na Figura 8.

Figura 8. Mecanismo de transferência de esforços na emenda.

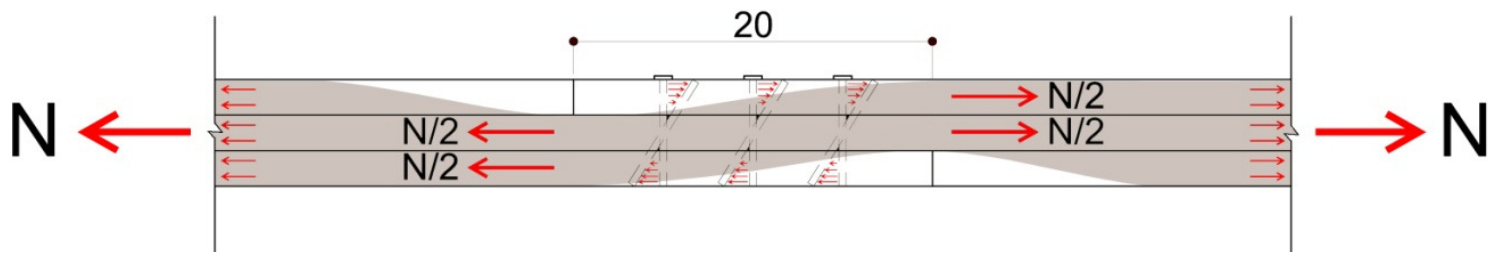

Fonte: Autores

A norma "Projeto de Estruturas de Madeira" NBR 7190-97 prevê uma resistência de projeto de $35 \mathrm{kgf}$ para esta ligação pregada. Os resultados de cada grupo de modelo estão apresentados no Quadro 1. A Figura 7 também apresenta aspecto típico deste tipo de ensaio, inclusive com a prescrição normativa pertinente. Portanto, observa-se que os valores encontrados para os pregos lisos são bastante compatíveis com a NBR 7190-97.

Os pregos lisos foram os que conduziram a menor capacidade para a ligação. Isto pode ser atribuído ao fator de que os pregos de ponta dobrada e os do tipo ardox, respectivamente, configuram um apoio na ponta dobrada ou possuem maior aderência à madeira. 
Quanto à rigidez das ligações em regime elástico, observa-se também que os pregos lisos produzem ligações mais deformáveis do que os outros dois tipos de pregos. Apesar disso, todos eles apresentaram ductilidade, característica muito importante para as ligações se tornarem mais previsíveis e seguras. Os pregos de ponta dobrada se comportam como uma viga hiperestática, biarticulada nas suas extremidades e, com o desenvolvimento de grandes deformações, ela passa a contar com a rigidez extensional além da rigidez a flexão. Este fato fez com que estes pregos obtivessem um desempenho superior ao do prego tipo ardox, em relação ao quesito rigidez.

Destaca-se também a variabilidade dos resultados. A resistência das ligações se mostrou mais variável do que a rigidez em fase elástica, e os pregos lisos obtiveram um desempenho mais variável do que os outros dois tipos de pregos. Nas fases iniciais, os pregos ainda apresentam baixa deformabilidade e, por isso, a rigidez das ligações fica menos dependente da heterogeneidade da madeira. Quanto à carga última, esta variabilidade cresceu para os 3 tipos de pregos porque ela ocorreu na madeira, por natureza heterogênea, principalmente, quando se trata de madeiras coníferas como o Pinus spp.

Quanto aos modos de ruptura, essas ligações apresentaram inicialmente grandes deformações, fletindo os seus pregos e, posteriormente, já com os pregos plastificados, a lâmina de madeira central rompia. $\mathrm{Na}$ ruptura, os deslocamentos da ligação correspondiam a deformações, cujos valores variaram entre $4 \%$ a $5 \%$, valores extremamente elevados quando comparados aos níveis de deformações correspondentes às resistências de cálculo.

Quadro 1 - Resultados de rigidez das emendas e resistência por prego.

\begin{tabular}{|l|c|c|l|c|c|l|c|c|}
\hline $\begin{array}{c}\text { Prego } \\
\text { A }\end{array}$ & $\begin{array}{c}\text { Rigidez } \\
\text { da } \\
\text { emenda } \\
\mathbf{2 0} \mathbf{~ c m} \\
(\mathbf{K N} / \mathbf{c m})\end{array}$ & $\begin{array}{c}\text { Resist. } \\
\text { por } \\
\text { prego } \\
\text { por } \\
\text { seção de } \\
\text { corte } \\
\text { (KN) }\end{array}$ & $\begin{array}{c}\text { Prego } \\
\text { B }\end{array}$ & $\begin{array}{c}\text { Rigidez } \\
\text { da } \\
\text { emenda } \\
\mathbf{2 0} \text { cm } \\
(\text { KN/cm) }\end{array}$ & $\begin{array}{c}\text { Resist. } \\
\text { por } \\
\text { prego } \\
\text { por } \\
\text { seção de } \\
\text { corte } \\
\text { (KN) }\end{array}$ & $\begin{array}{c}\text { Prego } \\
\text { C }\end{array}$ & $\begin{array}{c}\text { Rigidez } \\
\text { da } \\
\text { emenda } \\
\mathbf{2 0} \text { cm } \\
\text { (KN/cm) }\end{array}$ & $\begin{array}{c}\text { Resist. } \\
\text { por } \\
\text { prego } \\
\text { por } \\
\text { seção de } \\
\text { corte } \\
\text { (KN) }\end{array}$ \\
\hline PA 1 & 167 & 1,94 & PB 1 & 235 & 2,04 & PC 1 & 153 & 1,94 \\
\hline PA 2 & 169 & 1,89 & PB 2 & 190 & 2,80 & PC 2 & 175 & 2,15 \\
\hline PA 3 & 76 & 1,40 & PB 3 & 210 & 1,55 & PC 3 & 190 & 1,94 \\
\hline PA 4 & 118 & 0,97 & PB 4 & 195 & 1,29 & PC 4 & 163 & 1,51 \\
\hline PA 5 & 105 & 0,75 & PB 5 & 175 & 1,68 & PC 5 & 157 & 1,29 \\
\hline PA 6 & 101 & 0,97 & PB 6 & 249 & 1,03 & PC 6 & 193 & 2,47 \\
\hline MÉDIA & 123 & 1,32 & MÉDIA & 209 & 1,73 & MÉDIA & 172 & 1,88 \\
\hline DP & 37 & 0,51 & DP & 28 & 0,62 & DP & 17 & 0,43 \\
\hline CV & $31 \%$ & $38 \%$ & CV & $13 \%$ & $36 \%$ & CV & $10 \%$ & $23 \%$ \\
\hline
\end{tabular}

Fonte: Autores

Em todos os casos, a ruptura ocorreu na emenda, exceto uma vez. A ruptura da lâmina central sempre foi acompanhada pela presença de deformações excessivas dos pregos, e pela rotação dos pregos. Houve um caso de ruptura por cisalhamento longitudinal entre pregos, da linha de emenda, e destaca-se o afundamento das cabeças dos pregos na lâmina de madeira, no caso dos pregos de ponta dobrada. (Figuras 9 e 10) 
Figura 9. Fotos dos modelos rompidos. Grupo PA, PB e PC, respectivamente.
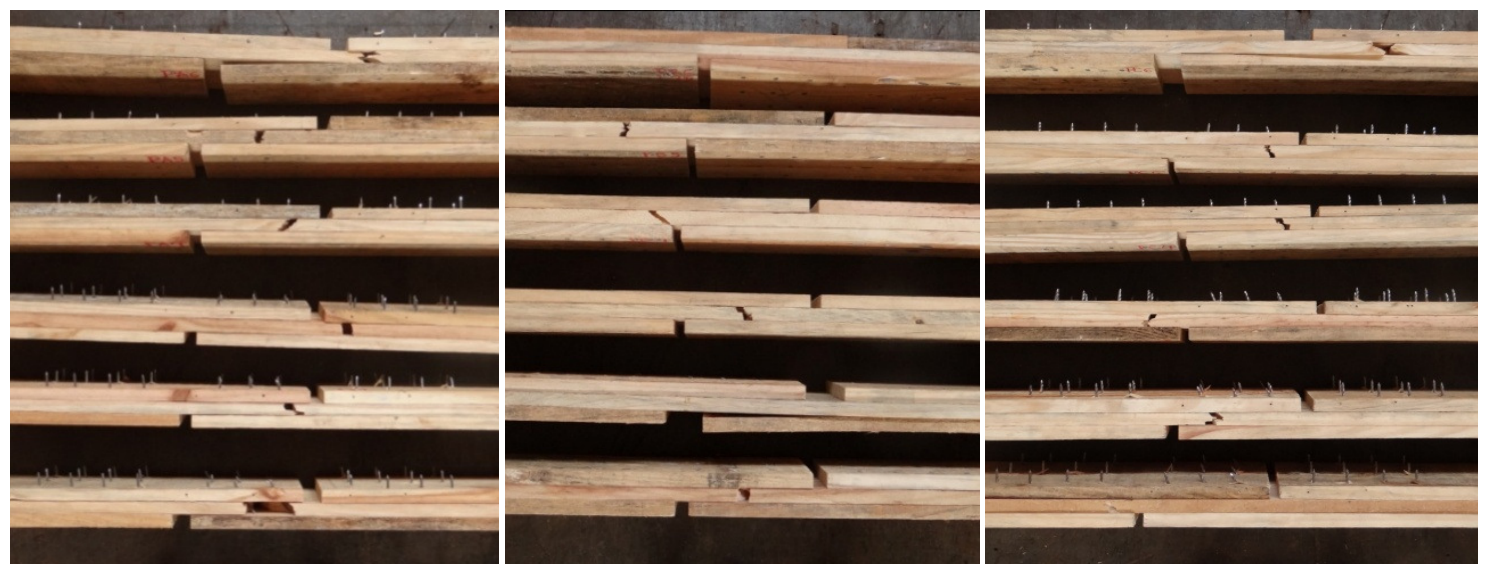

Fonte: Autores

O caso em que a ligação pregada rompe também por cisalhamento longitudinal da lâmina externa, o espaçamento adotado de aproximadamente 12 diâmetros entre pregos, excedeu o mínimo exigido de 6 diâmetros.

Figura 10. Fotos de modelos rompidos.
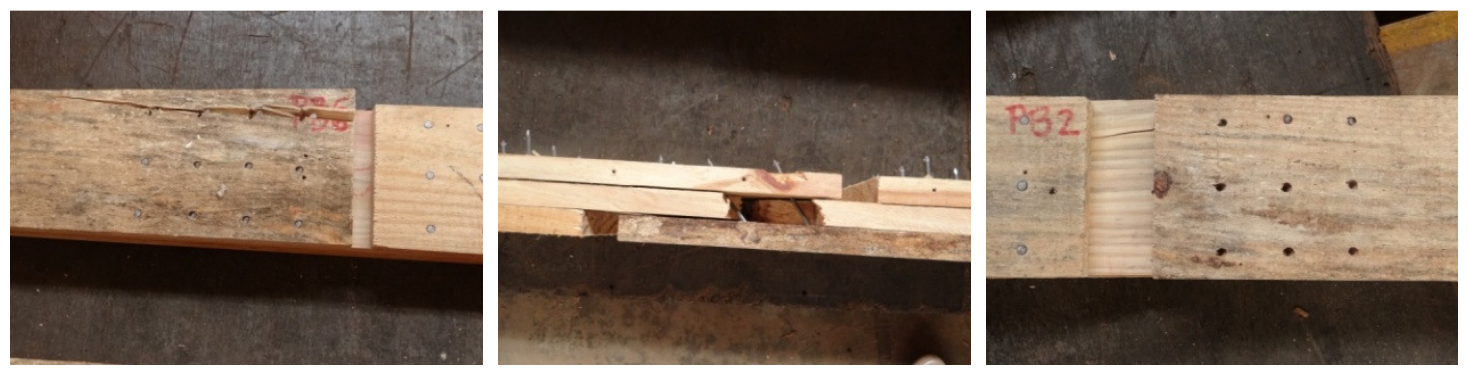

Fonte: Autores

\section{CONSIDERAÇÕES FINAIS}

Os resultados obtidos demonstram que nas vigas laminadas pregadas revela-se necessário garantir um espaçamento mínimo entre as emendas consecutivas de duas lâminas componentes, determinado a partir do nível de tensões aplicadas. Os resultados experimentais demonstram que os 3 tipos de ligação pregadas são diferentes entre si e, por isso, exigem para o correto dimensionamento destas ligações pregadas modelos matemáticos específicos, da Norma Projeto de Estruturas de Madeira - NBR 7190-97, ao contrário do seu modelo único.

As ligações com prego liso apresentaram a pior performance, tanto de resitência quanto de rigidez. As ligações com pregos com ponta dobrada obtiveram os melhores resultados de rigidez enquanto que as ligações com prego ardox os melhores resultados com relação à resistência. Estes dois tipos de ligação apresentaram desempenhos próximos entre si e superiores ao das ligações com pregos lisos.

As ligações estudadas apresentaram a necessária ductilidade. Mais estudos devem ser realizados para avaliar o comportamento do material para cargas de longa duração. Com efeito, os resultados experimentais indicam a possibilidade de melhoria do sistema de ligação das emendas de vigas em MLP e, consequentemente, do desempenho de rigidez e de resistência do sistema caibro treliçado. Estes resultados servirão como base para o desenvolvimento das próximas etapas do sistema. 


\section{AGRADECIMENTOS}

Aos que colaboraram para a execução do ensaio, técnicos laboratoristas Luiz Gustavo Patrocino e Carlos Alberto Duarte, estagiárias e demais membros do projeto. À Capes e Fundação Araucária, pelo apoio recebido.

\section{REFERÊNCIAS}

AMERICAN SOCIETY FOR TESTING MATERIALS - ASTM.ASTM D 245: Standard Test Methods for Mechanical Properties of Lumber and Wood-Base Structural Material, Philadelphia, 2002.

ASSOCIAÇÃO BRASILEIRA DE NORMAS TÉCNICAS, ABNT, NBR 7190: Projeto de estruturas de madeira. Rio de Janeiro, 1997. 107 p.

ASSOCIAÇÃO BRASILEIRA DE NORMAS TÉCNICAS, ABNT, NBR 11700: Madeira serrada de coníferas proveniente de reflorestamento para uso geral, Rio de Janeiro, 1990, 6 p.

BRITO, K. D.; MACCAGNAN, C. L.; PLETZ, E. Análise comparativa entre o Sistema Construtivo Convencional e o Sistema Caibro Treliçado. 2010. Apresentação de Trabalho no III Congresso Internacional de Arquitetura \& Urbanismo e Engenharia Civil, Água e Habitação. 2010.

CALIL JR., C.; ROCCO LAHR, F. A.; DIAS, A. A. Dimensionamento de elementos estruturais de madeira. 1 ed. Barueri: Editora Manole Ltda, 2003. 152 p.

DAMIANO, A. R. G.; SALES, A. Racionalização de estruturas de cobertura para habitação de interesse social utilizando madeiras de reflorestamento. In: ENCONTRO BRASILEIRO DE MADEIRAS E ESTRUTURAS DE MADEIRAS, 2004, Cuiabá, MT. Anais... Cuiabá, MT, 2004.

DUARTE, R. S.: Avaliação do Comportamento de Ligações com Parafusos AutoAtarraxantes em Vigas de MLC C. Dissertação de mestrado. Universidade Federal de Minas Gerais, Belo Horizonte, 248p, 2004. Orientador Prof. Dr. Edgar Vladimiro Mantilla Carrasco.

FOREST PRODUCTS LABORATORY. Wood Handbook: wood as an engineering material. General Technical Report (FPL-GTR-113). 1999, 463 p. Madison. Available from: $<$ http://www.fpl.fs.fed.us/documnts/fplgtr/fpl_gtr190.pdf > . Acesso em: 20 de maio de 2014.

GOÉS, J. L. N.; DIAS, A. A. Análise de vigas de madeira pregadas com seção composta I. São Carlos: Escola de Engenharia de São Carlos, USP, 2005. Cadernos de Engenharia de Estruturas, v. 7, n. 29, p. 57-77.

MOURA, J. D. M.; PLETZ, E; RECCO, E. G. Qualidade e processo produtivo da madeira para utilização em mobiliário. Londrina, 2012.

MOURA, J. D. M.; PLETZ, E; SAVINO, M. G., RECCO, E. G. Elaboração de manual de classificação visual estrutural para a madeira de Pinus spp, XIII Ebramem, Vitória /ES, 2012.

HALLER, P. Progress in timber joint development and modeling. Proceedings of the 5th World Conference on Timber Engineering, Montrex, Switzerland, Aug. 17-20, 1998, vol. 1, p. 337-344.

SMITH, I.; FOLIENTE, G. Load and Resistance Factor Design of Timber Joints: International Practice and Future Direction. Journal of Structural Engineering, Jan. 2002.

VALLE, I. M. R. A pré-fabricação de dois sistemas de cobertura com madeira de florestas plantadas: Estudos de casos: os assentamentos rurais Pirituba II e Sepé Tiaraju. São Carlos: Escola de Engenharia de São Carlos, USP, 2011. 352 p. Tese (Doutorado).

VALLE, I. M. R.; INO, A; SHIMBO, I. O sistema de cobertura VLP - vigas laminadas pregadas.- SP.In: Encontro Brasileiro em Madeira e Estruturas de Madeira, 11,. 2008 Londrina. Anais Londrina: EBRAMEM, 2008b. 1 SD-ROM. 